UDC 574.42; 902.26

Submitted: 01.02.2018

LBC 63.3(2)2

Accepted: 10.04.2018

\title{
CLIMATE ARIDIZATION IN THE DESERT-STEPPE ZONE: THE CAUSES, RESULTS AND IMPACT ON LIFE OF THE ANCIENT POPULATION ${ }^{1}$
}

\author{
Aleksandr V. Borisov \\ Institute of Physical-Chemical and Biological Problems of Soil Science, Russian Academy of Sciences, \\ Pushchino, Russian Federation \\ Maksim V. Eltsov \\ Institute of Physical-Chemical and Biological Problems of Soil Science, Russian Academy of Sciences, \\ Pushchino, Russian Federation \\ Sergey N. Udaltsov \\ Institute of Physical-Chemical and Biological Problems of Soil Science, Russian Academy of Sciences, \\ Pushchino, Russian Federation

\begin{abstract}
Aleksandr V. Bukhonov
Institute of Physical-Chemical and Biological Problems of Soil Science, Russian Academy of Sciences, Pushchino, Russian Federation
\end{abstract}

\begin{abstract}
The reason for aridization in the desert-steppe zone lies in the strengthening of the winter Asian anticyclone, which prevents the Mediterranean and Caspian cyclones from passing into the zone of desert steppes. These conditions provoke cold and snowless winters. The impact of aridization on soils consists in the accumulation of salts in the upper layers, the increase of carbonates and gypsum proportion, and in the intensification of soil erosion. Such conditions were very favorable for ancient cattle breeders, since they could allow the livestock to graze throughout the year and did not have to store fodder. The reverse process - increased humidization is associated with the weakening of the Asian winter anticyclone and the penetration of precipitation cyclones into the region of desert steppes. In such periods, toxic salts are washed out from the soils, humus content increases, $\oplus$ segregation of soil carbonate begins, and the reserve of moisture for plants is created. Winter precipitation, though, leads to the formation of a thick snow cover, icing of the plants and the creation of an ice crust. In these conditions grazing was impossible, and herds were subject to depletion and death.

Thus, during the periods of aridization, the most favorable conditions for pasturing developed in the desert steppe, while in humid periods, which were previously considered to be the most favorable, there was no opportunity for traditional pastoral farming. So, in the conditions of sharply arid climate in the middle - second half of the $3^{\text {rd }}$ millennium $\mathrm{BC}$, the catacomb cultures and post-catacomb cultural communities prospered in the desert steppe. The increase in the atmospheric humidity in the $19^{\text {th }}-18^{\text {th }} \mathrm{cc}$. BC resulted in the increase in winter precipitation, which made impossible the winter grazing. This was the reason for a well-known period of depopulation of the desert steppe in the Late Bronze Age.

The presented material is the result of the authors' joint research work: A. V. Borisov has developed the general conception of the research, reviewed literary sources and prepared the manuscript's text; M. V. Eltsov has conducted paleoclimatic reconstructions for the investigated region; S. N. Udaltsov has carried out the chemicalanalytical studies of the selected paleo-soil samples, and the general editing of the manuscript; A. V. Bukhonov has taken an active part in the field part of the study and discussed the proposed conception.

Key words: desert steppe, Bronze Age, anticyclone, aridization, soil, ancient cattle breeders.

Citation. Borisov A.V., Eltsov M.V., Udaltsov S.N., Bukhonov A.V. Climate Aridization in the Desert-Steppe Zone: the Causes, Results and Impact on Life of the Ancient Population. Vestnik Volgogradskogo gosudarstvennogo universiteta. Seriya 4, Istoriya. Regionovedenie. Mezhdunarodnye otnosheniya [Science Journal of Volgograd State University. History. Area Studies. International Relations], 2018, vol. 23, no. 3, pp. 52-62. (in Russian). DOI: (0) https://doi.org/10.15688/jvolsu4.2018.3.5
\end{abstract}




\title{
АРИДИЗАЦИЯ КЛИМАТА В ПУСТЫННО-СТЕПНОЙ ЗОНЕ: ПРИЧИНЫ, ФОРМЫ ПРОЯВЛЕНИЯ И ВЛИЯНИЕ НА ЖИЗНЬ ДРЕВНЕГО НАСЕЛЕНИЯ ${ }^{1}$
}

\author{
Александр Владимирович Борисов \\ Институт физико-химических и биологических проблем почвоведения РАН, \\ г. Пущино, Российская Федерация \\ Максим Витальевич Ельцов \\ Институт физико-химических и биологических проблем почвоведения РАН, \\ г. Пущино, Российская Федерация

\section{Сергей Николаевич Удальцов} \\ Институт физико-химических и биологических проблем почвоведения РАН, \\ г. Пущино, Российская Федерация

\section{Александр Вячеславович Бухонов} \\ Институт физико-химических и биологических проблем почвоведения РАН, \\ г. Пущино, Российская Федерация
}

Аннотация. Причиной аридизации в пустынно-степной зоне является усиление зимнего азиатского антициклона, в результате чего средиземноморские и каспийские циклоны не проходят в зону пустынных степей. В этих условиях начинаются холодные бесснежные зимы. В почвах аридизация проявляется в том, что происходит накопление солей в верхних горизонтах, увеличивается содержание карбонатов и гипса, усиливается эрозия. Для древних скотоводов в такие периоды складываются очень благоприятные условия, что позволяет им выпасать скот в течение всего года и не запасать корм. Обратный процесс - гумидизация, связанная с ослаблением азиатского зимнего антициклона и проникновением в регион пустынных степей циклонов, которые приносят осадки в виде дождя и снега. В такие периоды в почвах вымываются токсичные соли, увеличивается содержание гумуса, формируются сегрегационные формы карбонатных новообразований, и создается запас влаги для растений. Однако зимние осадки приводят к формированию мощного снежного покрова, обледенению растений и созданию ледяной корки. В этих условиях выпас скота становится невозможным, что приводит к истощению и гибели стада. Таким образом, в периоды аридизации в степи складывались максимально благоприятные условия для скотоводства, в то время как в гумидные периоды, которые ранее считались наиболее благоприятными, возможности для ведения традиционного пастушеского хозяйства отсутствовали. Так, в условиях резко выраженной аридизации климата в середине - второй половине III тыс. до н. э. в пустынной степи наступает расцвет катакомбных культур и посткатакомбных культурных общностей. Увеличение атмосферной увлажненности в XIX-XVIII вв. до н. э. и связанный с ним рост количества осадков в зимний период сделали невозможным зимний выпас скота, что стало причиной известного периода депопуляции пустынной степи в позднем бронзовом веке.

Представленный материал является результатом совместной работы авторов: А.В. Борисову принадлежит общая концепция работы, обобщение литературных данных и подготовка основного текста рукописи; М.В. Ельцовым проведены палеоклиматические реконструкции для исследованного региона, С.Н. Удальцов осуществил химико-аналитическое исследование отобранных палеопочвенных образцов, а также выполнил общее редактирование рукописи и подготовку ее к публикации; А.В. Бухонов принял активное участие в полевой части исследования и обсуждении предложенной концепции.

Ключевые слова: пустынная степь, эпоха бронзы, антициклон, аридизация, почва, древние скотоводы.

Цитирование. Борисов А. В., Ельцов М. В., Удальцов С. Н., Бухонов А. В. Аридизация климата в пустынно-степной зоне: причины, формы проявления и влияние на жизнь древнего населения // Вестник Волгоградского государственного университета. Серия 4, История. Регионоведение. Международные отношения. 2018. - T. 23, № 3. - C. 52-62. - DOI: https://doi.org/10.15688/jvolsu4.2018.3.5 


\section{МЕЖДИСЦИПЛИНАРНЫЕ ИССЛЕДОВАНИЯ}

Тесное сотрудничество археологов и специалистов естественнонаучных дисциплин, в первую очередь почвоведов, в изучении археологических памятников древности и средневековья привело к тому, что в лексикон археологов проникли и стали общепринятыми термины и понятия из арсенала почвоведения, геохимии, геофизики, ландшафтоведения, почвенной микробиологии и других наук. Среди этих терминов одним из наиболее часто употребляемых при рассмотрении вопросов сложения и развития древних обществ является термин «аридизация». При этом в представлении археологов, а зачастую и самих почвоведов нет четкого представления о причинах, форме проявления и последствиях указанного процесса. Это приводит к тому, что термином зачастую оперируют некорректно, а его использование для объяснения тех или иных культурно-исторических процессов и явлений выглядит по меньшей мере неубедительно. Как правило, говоря об аридизации, подразумевают некие процессы, связанные с уменьшением количества осадков, повышением температур, угнетением растений и т. д., которые более соответствуют понятию «засуха». Такая трактовка указанного термина в значительной мере обедняет и искажает его смысл, не говоря уже о том, что внутренняя сущность данного процесса при этом не раскрывается вообще. В этой связи цель настоящей статьи заключается в рассмотрении причин аридизации, механизмов проявления этого процесса и оценке его влияния на жизнь древнего населения.

В качестве объекта исследований предлагается взять пустынно-степную зону юговостока Русской равнины - регион, включающий южные районы Волгоградской области, Республику Калмыкия, восточные районы Ростовской области и север Ставропольской возвышенности.

Этот регион на сегодняшний день наиболее полно исследован с позиций археологического почвоведения, так как именно здесь складывалось археологическое почвоведение как новое междисциплинарное научное направление [12, с. 190], и именно археологическое почвоведение привнесло в археологию термин «аридизация». Поэтому рассмотрение природы этого явления следует начать с тех проявлений данного процесса, которые можно увидеть, исследуя почвы, погребенные под курганами в аридные и гумидные периоды. На рисунке 1 представлена схема изменения свойств почв пустынных степей при аридиза-

Стратиграфия профиля погребенных и современных почв
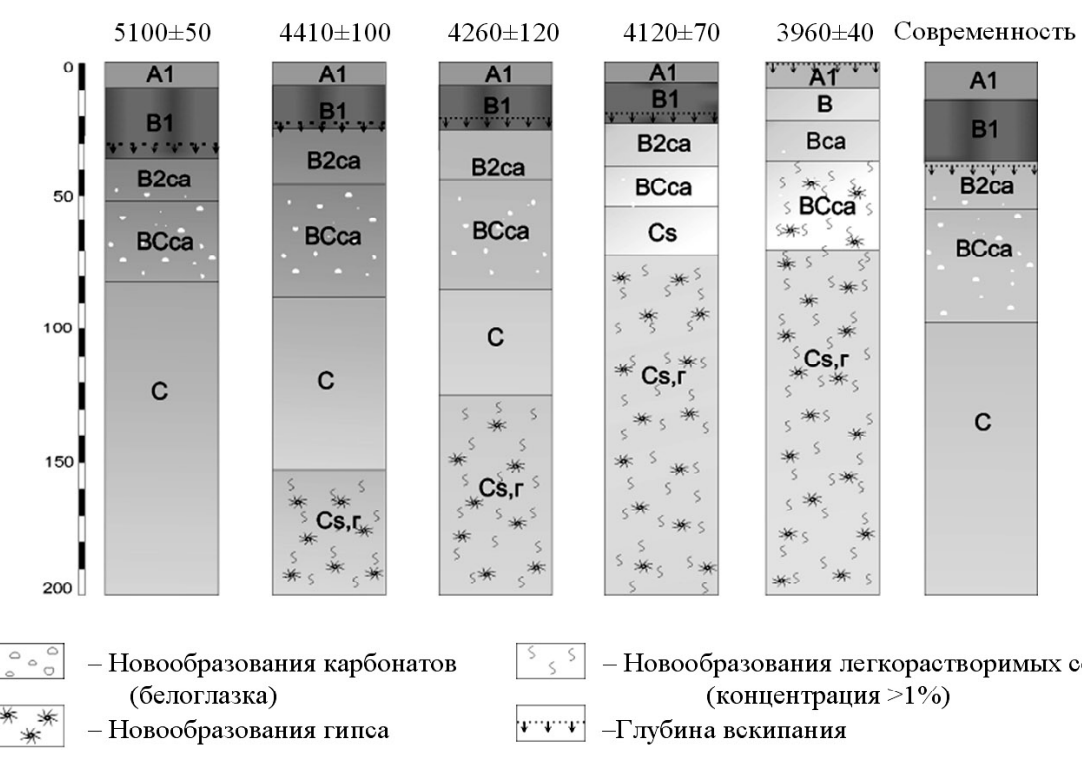

Рис. 1. Изменение свойств почв пустынных степей при аридизации (5100-4000 л.н.) и гумидизации климата (современность)

Fig. 1. The changes of soil properties in the desert steppe zone under condition of increasing climate aridity (5100-4000 years ago) and humidity (present days) 
ции и гумидизации климата. Так, прогрессирующая аридизация вызывает сокращение мощности гумусового горизонта в результате активизации эрозии, причиной которой, в свою очередь, является более изреженный растительный покров, также обусловливающий снижение скорости гумусонакопления. В результате усиления испарения влаги с поверхности не защищенной растениями почвы происходит накопление солей в верхней части почвенного профиля и формирование горизонта солевой аккумуляции в корнеобитаемом слое близко к поверхности почвы. Токсичные слои оказывают угнетающее действие на растения, что становится причиной дальнейшего уменьшения проективного покрытия, вызывающего вышеописанные процессы. Те же процессы усиления испарения приводят к накоплению карбонатов в верхней части почвенного профиля и подъему к поверхности линии вскипания. Сегрегационные формы карбонатов при этом не формируются. Увеличивается содержание гипса в нижних горизонтах почвы, становится менее выраженным или полностью затухает солонцовый процесс.

Обратная картина наблюдается при увеличении количества осадков и связанного с этим процесса гумидизации. В первую очередь из корнеобитаемого слоя почвы вымываются токсичные соли, что обеспечивает более благоприятные условия для роста растений, увеличивается их частота, появляются корневищные злаки, что резко снижает эрозию и вызывает рост гумусового горизонта вверх. При этом мощность гумусового горизонта возрастает за счет накопления гумуса и прокрашивания гумусом нижележащих горизонтов. Снижается линия вскипания; глубокое промачивание и последующее иссушение приводят к формированию сегрегационных форм карбонатных новообразований. Оптимизация условий для почвенной микробиоты обусловливает перестройку почвенного микробного сообщества, возрастание магнитной восприимчивости верхних горизонтов почвы. Так выглядят основные почвенные индикаторы аридизации и гумидизации климата.

Теперь, назвав особенности изменения почвенных свойств в условиях аридизации и гумидизации, обратимся к исследованию климатических изменений, которые вызывают эти процессы. В качестве эталонного участка пустынных степей рассмотрим климатические характеристики г. Элисты. Среднегодовые данные по количеству осадков и температуре приведены на рисунке 2. Несмотря на весьма существенное варьирование показателей теплои влагообеспеченности, в целом климатические условия довольно стабильные. Тепловые ресурсы велики - сумма температур воздуха выше $10{ }^{\circ} \mathrm{C}$ составляет $3400-3600{ }^{\circ} \mathrm{C}$. Годовое количество осадков колеблется от 210 до 340 мм, продолжительность теплого периода 240-275 дней [2, с. 15].

Как известно, основным фактором, определяющим климат пустынно-степной зоны,

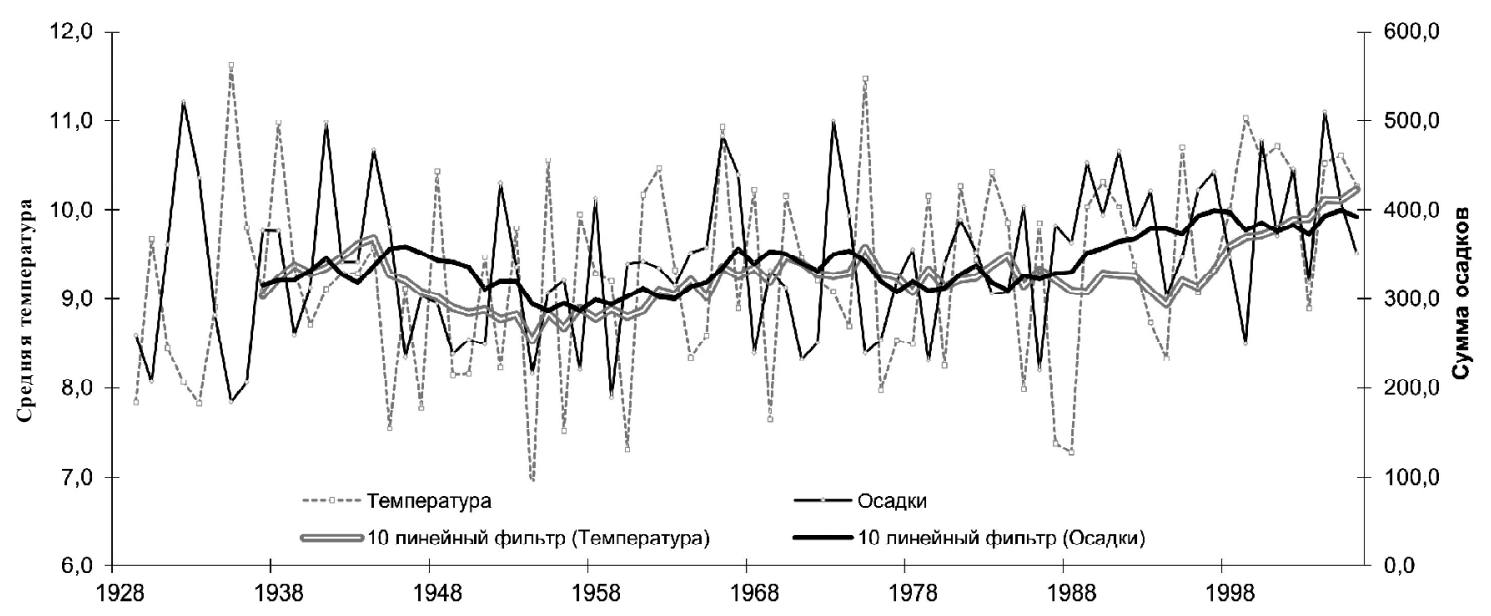

Рис. 2. Среднегодовые данные по температуре и количеству осадков в пустынно-степной зоне (метеостанция г. Элиста)

Fig. 2. Average annual data on temperature and precipitation in desert-steppe zone (Elista weather station) 
является азиатский антициклон [2, с. 14]. Его проявления в теплый и холодный сезоны года различны. В летний период азиатский антициклон обеспечивает формирование мощной области высокого давления и высоких температур. В этих условиях в пустынно-степной зоне осадки принято считать неэффективными [18, с. 43], так как они промачивают почву не более чем на 30 см и не оказывают влияния на солевой профиль почв [6, c. 35-36]. В пустынно-степной зоне при выраженных признаках солонцового процесса глубина промачивания почв в летний период еще меньше [7, с. 97; 13, с. 144-166]. Естественно, при таком режиме увлажнения все указанные выше почвенные диагностические параметры аридизации не будут изменяться. Летние осадки не вызывают изменений и в составе фитоценозов, так как большая их доля непродуктивна и теряется с поверхностным стоком и испарением в течение первых-вторых суток после дождя [2, с. 14]. В результате растения не успевают отреагировать на изменение увлажненности.

Варьирование количества летних осадков довольно значительное (рис. $3, a$ ). В отдельные годы за летний период выпадает менее 6070 мм осадков, в то время как в наиболее благоприятные годы этот показатель составляет 250-300 мм. Но даже столь высокие показатели влагообеспеченности не вызывают изменения почвенных свойств.

Единственным показателем, на который влияют летние осадки, является отавность. Так, в частности, показано, что в условиях полупустынной зоны 10 дополнительных поливов в норме 5 мм обеспечили увеличение массы отавы на $27 \%$ [1, с. 52]. Пять дополнительных поливов в норме 10 мм обеспечили прирост отавы на $176 \%$ [1, с. 42]. Особенно сильный эффект оказывают летние осадки на молодые растения [4, с. 12]. Это обстоятельство может быть очень важным, так как отава является одним из важнейших факторов для скотоводства в условиях ограниченного выбора сезонных пастбищ.

В целом влияние летних осадков не приводит к заметным изменениям почвенных свойств и состава фитоценоза, так как не снимает основного ограничивающего фактора в пустынностепной зоне - высокого засоления почв.
Особенно высока роль азиатского антициклона в зимний период года. При создании барического максимума осадки зимой практически не выпадают; устанавливается сухая и морозная погода. В результате не формируется снеговой покров, или же вода при таянии стекает по замерзшей почве, не впитываясь в нее [7, с. 101-102; 18, c. 13]. В результате почва быстро пересыхает в условиях частых весенних ветров восточных румбов [2, с. 14], что приводит к угнетению растений. В почвенном профиле при этом происходит уменьшение мощности гумусового горизонта, сокращение запасов гумуса, приближение к поверхности почвы карбонатного горизонта; резко усиливается засоление.

При ослаблении азиатского антициклона на территорию пустынных степей вторгаются влажные воздушные массы южно-каспийских и средиземноморских циклонов, а также проходят мощные штормовые атлантические циклоны, вызывающие обильные снегопады и метели [2, с. 14]. Так как циклоны обычно заканчиваются похолоданием, формируется довольно мощный снеговой покров, который при весеннем таянии обеспечивает накопление значительных объемов продуктивной влаги в почве. В этом заключается определяющий эффект зимних осадков на водный баланс пустынно-степных почв $[6$, с. $34 ; 7$, с. $97 ; 13$, с. $144-166]$. Если зимой снег ложится на незамерзшую почву, если часто бывают оттепели и дождь, если период весеннего снеготаяния продолжительный, из почвы вымываются легкорастворимые соли, и создается большой влагозапас для растений $[18$, с. 43]. Наибольший весенний влагозапас образуется в результате регулярных зимних оттепелей и дождей, когда вся влага впитывается в почву [6, с. 47-50]. $\mathrm{B}$ почве при этом происходит накопление гумуса, рост гумусового горизонта, вымывание водорастворимых солей в нижнюю часть почвенного профиля или за его пределы, снижение глубины вскипания, формирование крупной хорошо выраженной белоглазки, увеличение магнитной восприимчивости в верхних горизонтах и т. д. Следовательно, этот период также будет диагностироваться как период гумидизации. 

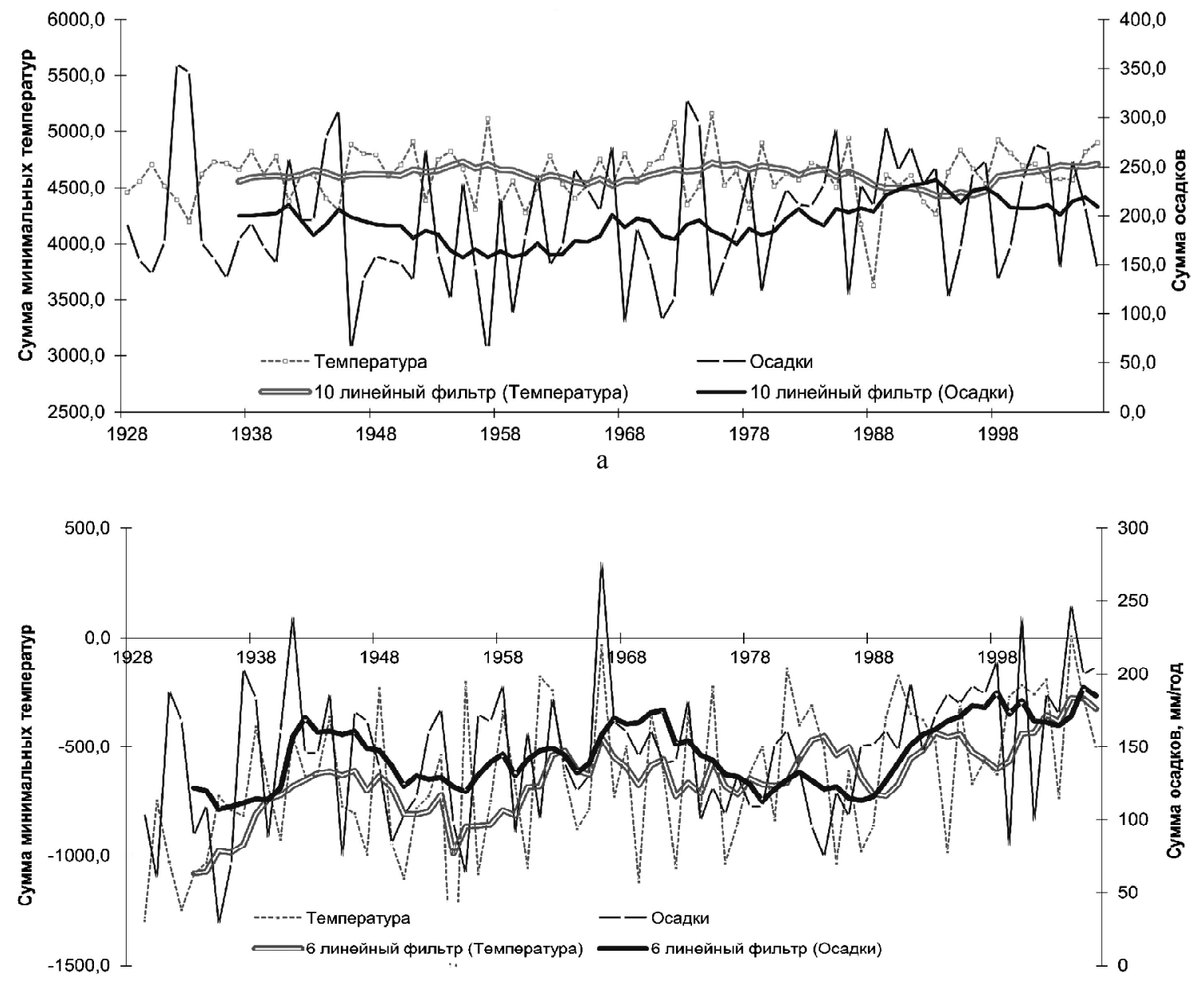

6

Рис. 3. Изменения максимальных летних температур и осадков ( $a$ ) и минимальных зимних температур и осадков (б) в пустынно-степной зоне (по данным метеостанции г. Элиста)

Fig. 3. Changes in maximum summer temperatures and precipitation $(a)$ and minimum winter temperatures and precipitation $(b)$ in the desert-steppe zone (according to the Elista weather station)

Уникальной особенностью региона пустынных степей является четко выраженная синхронность изменений температур осадков зимнего периода (рис. 3, б). Как правило, чем холоднее зима, тем меньше осадков выпадает в холодное время года. Так проявляется действие азиатского антициклона и его влияние на климат пустынно-степной зоны.

Таким образом, причиной аридизации в пустынно-степной зоне является все большее уменьшение нормы осадков в холодный период года, связанное с усилением азиатского зимнего антициклона. Обратный процесс - гумидизация - происходит в условиях мягкой зимы с обильными осадками, высоким снежным покровом, частыми оттепелями. Осадки летнего периода практически не влияют на свойства почв.
Далее, зная, как изменяется внутригодовой ход осадков в условиях аридизации и гумидизации, можно оценить последствия того и другого процессов на жизнь древнего населения пустынных степей. Основу экономики всех населявших данный регион культур с момента возникновения производящего хозяйства до наших дней составляло скотоводство. Никакая иная модель хозяйства не могла обеспечить выживание общества при данных климатических условиях [21, с. 317]. Наличие земледелия на ранних этапах развития общества не доказано [14, с. 129]. Выпасая скот, население на протяжении всего года перемещалось в достаточно узких экологических нишах; меридиональные перекочевки появляются только в раннем железном веке. При этом сама экономическая модель пастушес- 
кого скотоводства трансформировалась весьма незначительно - изменялся только период продолжительности стоянок и соотношение времени пребывания в стационарном стоянии ко времени движения [23, p. 6], а также происходило изменение состава стада с увеличением доли мелкого рогатого скота [20, с. 56]. В самом простом случае в условиях летних засух общество древних скотоводов становилось более мобильным.

Значительно более сложной задачей являлся выпас скота в зимний период. И здесь особенно ярко проявлялась роль зимних осадков. Приход циклона в зимний период начинается с многодневных осадков, туманов, резкого ветра. В этих условиях скот теряет ориентировку, скучивается, начинается так называемая вялая пастьба. При этом высота снежного покрова может достигать нескольких десятков сантиметров, что очень затрудняет тебеневку, так как скот тратит больше энергии на добывание корма, чем получает энергии с кормом. В «хвосте» циклона наступает очень холодная погода, формируется наст, растения покрываются ледяной коркой. При наличии на поверхности снега прослойки льда толщиной около 5 мм скот ранит ноги и не может передвигаться. При дальнейшем похолодании снег становится более плотным, сыпучим. В этих условиях тебеневка мелкого рогатого скота становится неэффективной уже при мощности снегового покрова на уровне 5 см [2, с. 92]. Пастбища становятся доступными для животных лишь после того, как ветер частично сдует снег с водоразделов и северных склонов, но это не всегда происходит, так как может начаться новый цикл погодных изменений, связанных с приходом очередного циклона. В результате длительного невыпасного периода скот слабеет, начинается массовый падеж. Судьба людей, потерявших свое стадо, очевидна, учитывая абсолютную зависимость их от животных. Причины ухода с исторической сцены обществ древних скотоводов - высокий снеговой покров в зимний период и чередование оттепелей и морозов. Что касается свойств почвы, то в такие периоды проявляются все перечисленные выше признаки гумидизации.

Следует еще раз подчеркнуть, что все это относится только к зоне пустынных сте- пей. В более северных и западных регионах, в зоне сухих степей и лесостепи имелись возможности запасать корма на невыпасные дни, в распоряжении древних скотоводов были также поймы рек, где всегда имеется высокое разнотравье, камыш, кустарники и деревья. В пустынно-степной зоне подобных условий не было.

C наступлением аридизации, напротив, складывались исключительно благоприятные условия для скотоводов. Отсутствие весенней влагозарядки, безусловно, резко снижало продуктивность пастбищ и вызывало существенные изменения в составе фитоценозов выпадание злаков и преимущественное развитие кустарничковых, в первую очередь полыней. Но именно полыни становились основой зимнего корма, так как эфирные масла, придающие полыни ее специфический запах и токсичные в большом количестве для животных, распадаются с наступлением холодов [2, c. 92]. Поэтому в зимний период полынь становится высококачественном кормом. В свою очередь, в условиях сухих и бесснежных зим скот практически не тратит энергию на тебеневку, нагуливает жир и легко переносит низкие температуры.

Наглядным примером расцвета древних обществ в условиях аридизации стала эпоха средней бронзы и посткатакомбный блок культур. Ранее было показано, что первые признаки аридизации начали появляться в почвах еще в XXVIII-XXVII вв. до н. э. [9, c. 190]. Прогрессирующее развитие аридизации продолжалось в середине - второй половине III тыс. до н. э. [3; 11; 22]. Наиболее резко выраженные аридные условия сложились во время существования в пустынно-степной зоне лолинской культуры XXII-XVIII вв. до н. э. [15, с. 280-291; 16]. Выживание обществ в период сильной аридизации стало возможным благодаря изменениям хозяйственной модели, отказу от выращивания крупного рогатого скота и специализации на разведение овец. Когда начался переход на выращивание мелкого рогатого скота - точно сказать трудно, но уже в составе стада восточно-манычской катакомбной культуры в XXVI-XXII вв. до н. э. доля крупного рогатого скота не превышала $20 \%$ [5, с. $14 ; 19$, с. 66 , табл. 3], а в стаде лолинской культуры коров практически 
не было. Более того, в лолинской культуре, как и в целом в посткатакомбном мире, складывается своего рода культ овцы: лопатки и конечности этих животных становятся «визитной карточкой» эпохи [15, с. 39-44]. Это неудивительно, учитывая особую неприхотливость овец и их способность довольствоваться минимумом корма самого низкого качества. Именно эти особенности позволили выжить населению посткатакомбных общностей в условиях пика аридизации на рубеже IIIII тыс. до н. э.

На сегодняшний день довольно четко установлено, что благоприятные для скотоводов условия с холодными малоснежными зимами существовали до XXII-XVIII вв. до н. э., после чего начался период гумидизации. В северной части ареала посткатакомбных культурных формирований возникает покровская культура и более поздние культуры срубного мира, для времени существования которых реконструированы довольно гумидные палеоэкологические условия [10, c. $145-150 ; 11$, с. $81 ; 12$, с. $179-180]$. Однако в этих регионах гумидизация климата не привела к каким-либо негативным последствиям, напротив, способствовала демографическому росту и расцвету срубной культурной традиции. На наш взгляд, это объясняется возможностью запасать корма и пасти скот в поймах рек. В этот период возникают стационарные поселения, в стаде вновь появляется крупный рогатый скот, что опять же предполагает как улучшение кормовой базы, так и запасание кормов на зимние невыпасные дни. Но практически все срубные памятники расположены севернее широты современного Волгограда. Южнее, на севере Астраханской области и севере Калмыкии, могильники срубной культуры еще встречаются, но поселений нет. Еще южнее, в пустынно-степной зоне, населения практически не было [15, с. $338 ; 17]$. Причинами тому являются гумидизация климата и отсутствие хозяйственной модели, соответствующей новой природной ситуации [8, с. 48-60]. В результате вся территория пустынных степей обезлюдела почти на тысячелетие: эпоха поздней бронзы практически не представлена в данном регионе [17]. Таковы были последствия гумидизации климата и оптимизации природных условий в пустынно-степной зоне. Этот регион вновь стал доступен для обитания лишь после того, как население в полной мере овладело всеми хозяйственными, политическими и социальными инструментами номадизма. Произошло это только в сарматскую эпоху.

Подводя итог, можно заключить, что аридизация в пустынно-степной зоне выражается в усилении зимнего азиатского антициклона и сокращении количества осадков в холодное время года. В результате устанавливается холодная сухая погода с малой мощностью снегового покрова или его полным отсутствием. В эти периоды создаются наиболее благоприятные условия для содержания скота - основы экономики древних обществ. Обратный процесс - гумидизация - происходит при ослаблении зимнего антициклона и увеличении количества осадков. В этот период наблюдается неустойчивая зимняя погода с частыми оттепелями, дождями, туманами, за которыми следуют периоды похолодания, сопровождающиеся обледенением травы, формированием ледяной корки и увеличением мощности снегового покрова. В этих условиях увеличивается число невыпасных дней; скот слабеет, начинается массовый падеж, потеря стада и гибель населения.

Известная лакуна в освоении пустынных степей в эпоху поздней бронзы, по всей видимости, связана с периодом гумидизации климата.

Абсолютная зависимость древних обществ от климатических условий наиболее ярко проявляется в пустынно-степной зоне, где единственной возможной экономической моделью является экстенсивное скотоводство с круглогодичным содержанием скота на подножном корму. Отсутствие условий для меридиональных перекочевок очень сильно ограничивало возможности данной экономической модели и делало ее чрезвычайно зависимой от климатических условий. Эта зависимость существовала до раннего железного века и исчезла с возникновением крупных социально-политических образований, охватывающих разные природные зоны, что позволило ввести сезонную смену пастбищ. 


\section{ПРИМЕЧАНИЕ}

1 Исследование выполнено в рамках Государственного задания Министерства образования и науки Российской Федерации, проект АААА-А18$118013190175-5$ «Развитие почв в условиях меняющегося климата и антропогенных воздействий».

\section{СПИСОК ЛИТЕРАТУРЫ}

1. Абрамова, М. М. К вопросу об эффективности летних осадков в условиях засушливого климата / М. М. Абрамова // Почвоведение. - 1962. № 9. - C. 4-53.

2. Агроклиматические ресурсы Калмыцкой АССР. - Л. : Гидрометиздат, 1974. - 124 с.

3. Александровский, А. Л. Эволюция почв и географическая среда / А. Л. Александровский, Е. И. Александровская. - М. : Наука, 2005. - 223 с.

4. Алпатьев, А. М. Почвоувлажнительный и биологический эффект атмосферных осадков / А. М. Алпатьев // Почвоведение. - 1959. - № 2.-С. 12-14.

5. Андреева, М. В. Восточноманычская катакомбная культура (анализ погребальных памятников) : автореф. дис. ... канд. ист. наук / Андреева Марина Владимировна. - М., 2008. - 27 с.

6. Афанасьева, Е. А. Водно-солевой режим обыкновенных и южных черноземов Юго-Востока европейской части СССР / Е. А. Афанасьева. - М. : Наука, 1980. - 216 с.

7. Базыкина, Г. С. Водный режим и баланс мелиорируемых в культурных биогеоценозах / Г. С. Базыкина // Биогеоценотические основы освоения полупустыни Северного Прикаспия. - М. : Наука, 1974. $-359 \mathrm{c}$.

8. Борисов, А. В. Аридизация: формы проявления и влияние на население степной зоны в бронзовом веке / А. В. Борисов, Р. А. Мимоход // Российская археология. - 2017. - № 2. - С. 48-60.

9. Борисов, А. В. Палеопочвы и климат Ергеней в эпоху бронзы (IV-II тыс. до н. э.) / А. В. Борисов, Т. С. Демкина, В. А. Демкин. - М. : Наука, 2006. $210 \mathrm{c}$.

10. Борисов, А. В. Палеопочвы и природные условия южнорусских степей в посткатакомбное время / А. В. Борисов, Р. А. Мимоход, В. А. Демкин // КСИА. - М., 2011. - Вып. 225. - С. 144-154.

11. Волго-Донские степи в древности и средневековье (по материалам почвенно-археологических исследований) / В. А. Демкин, А. В. Борисов, T. С. Демкина [и др.]. - Пущино : SYNCHROBOOK, 2010. $-120 \mathrm{c}$.

12. Демкин, В. А. Палеопочвоведение и археология / В. А. Демкин. - Пущино : ОНТИ НЦБИ АН СССР, 1997. $-213 \mathrm{c}$.
13. Ковда, В. А. Водно-солевой режим почв центральной части Каспийской равнины / В. А. Ковда, А. Ф. Большаков // Труды конференции по почвоведению и физиологии растений. - Т. 1. - Саратов, 1937. - С. 144-166.

14. Междисциплинарная интеграция в археологии / отв. ред.: Е. Е. Черных, Т. Н. Мишина. - М. : Институт археологии РАН, 2016. - 384 с.

15. Мимоход, Р. А. Лолинская культура. Северо-западный Прикаспий на рубеже среднего и позднего периодов бронзового века / Р. А. Мимоход // Материалы охранных археологических исследований. - Т. 16. - М. : ИА РАН, 2013. - 568 с.

16. Мимоход, Р. А. Радиоуглеродная хронология блока посткатакомбных культурных образований / Р. А. Мимоход // КСИА. - М. : ИА РАН, 2011. Вып. 225. - С. 28-53.

17. Мимоход, Р. А. Срубная культура Северозападного Прикаспия / Р. А. Мимоход // Труды IV (XX) Всероссийского археологического съезда в Казани. - Т. 1. - Казань, 2014. - С. 609-614.

18. Роде, А. А. Водный режим и баланс целинных почв полупустынного комплекса / А. А. Роде // Водный режим почв полупустыни. - М. : Изд-во АН СССР, 1963. - С. 5-83.

19. Шилов, В. П. Очерки по истории древних племен Нижнего Поволжья / В. П. Шилов. - Л. : Наука, 1975. - 208 с.

20. Шишлина, Н. И. Потенциальный сезоннохозяйственный цикл носителей катакомбной культуры Северо-Западного Прикаспия: проблема реконструкции / Н. И. Шишлина // Сезонный экономический цикл населения Северо-Западного Прикаспия в бронзовом веке. - М., 2000. - С. 54-71. (Труды ГИМ ; вып. 120).

21. Шишлина, Н. И. Северо-западный Прикаспий в эпоху бронзы (V-III тыс. до н. э.) / Н. И. Шишлина. - М., 2007. - 400 с. - (Труды ГИМ ; вып. 165).

22. Borisov, A. Climate changes and soil evolution in desert steppe zone of Russian Plain during the Bronze Age / A. Borisov, N. Shishlina // International Multidisciplinary Scientific GeoConference Surveying Geology and Mining Ecology Management SGEM, SGEM 2017. Conference Proceedings. - 2017. - Vol. 17, iss. 32. -P. 77-84. - DOI: 10.5593/sgem2017/32/S13.011.

23. Wendrich, W. The Archaeology of Mobility: Definitions and research approaches / W. Wendrich, H. Barnard // The Archaeology of Mobility. Old World and New World Nomadism / ed. by H. Barnard and W. Wendrich. - Los Angeles : Cotsen Institute of Archaeology Press, 2008. - P. 1-21.

\section{REFERENCES}

1. Abramova M.M. K voprosu ob effektivnosti letnikh osadkov v usloviyakh zasushlivogo klimata 
[About the Effectiveness of Summer Precipitation in the Conditions of Dry Climate]. Pochvovedenie, 1962, no. 9, pp. 4-53.

2. Agroklimaticheskie resursy Kalmytskoy ASSR [Agroclimatic Resources of the Kalmykia ASSR]. Leningrad, Gidrometizdat Publ., 1974. 124 p.

3. Aleksandrovskiy A.L., Aleksandrovskaya E.I. Evolyutsiya pochv $i$ geograficheskaya sreda [Evolution of Soils and Geographical Environment]. Moscow, Nauka Publ., 2005. 223 p.

4. Alpatyev A.M. Pochvouvlazhnitelnyy i biologicheskiy effekt atmosfernykh osadkov [SoilMoisturizing and Biological Effect of Atmospheric Precipitation]. Pochvovedenie, 1959, no. 2, pp. 12-14.

5. Andreeva M.V. Vostochnomanychskaya katakombnaya kultura (analiz pogrebalnykh pamyatnikov): avtoref. dis. ... kand. ist. nauk [The East-Manych Catacomb Culture (Analysis of Funerary Sites). Cand. hist. sci. abs. diss.]. Moscow, 2008. 27 p.

6. Afanasyeva E.A. Vodno-solevoy rezhim obyknovennykh i yuzhnykh chernozemov YugoVostoka evropeyskoy chasti SSSR [The Water-Salt Regime of Typical and Southern Black Soils in the South-East of the European Part of the USSR]. Moscow, Nauka Publ., 1980. 216 p.

7. Bazykina G.S. Vodnyy rezhim i vodnyy balans melioriruemykh pochv v kulturnykh biogeotsenozakh [The Water Regime and Water Balance of Reclaimed Soils in Artificial Biogeocenoses]. Biogeotsenoticheskie osnovy osvoeniya polupustyni Severnogo Prikaspiya [Biogeocenotic Basis for the Development of the SemiDesert of the Northern Caspian]. Moscow, Nauka Publ., 1974, pp. 63-147.

8. Borisov A.V., Mimokhod R.A. Aridizatsiya: formy proyavleniya i vliyanie na naselenie stepnoy zony v bronzovom veke [Aridization: Forms and Impact on the Population of the Desert Steppe Zone in the Bronze Age]. Rossiyskaya arkheologiya [Russian Archaeology], 2017, no. 2, pp. 48-60.

9. Borisov A.V., Demkina T.S., Demkin V.A. Paleopochvy i klimat Ergeney $v$ epokhu bronzy (IVII tys. do n.e.) [Paleosoils and the Climate of Ergeny Upland in the Bronze Age (the $4^{\text {th }}-2^{\text {nd }}$ millennia BC)]. Moscow, Nauka Publ., 2006. 210 p.

10. Borisov A.V., Mimokhod R.A., Demkin V.A. Paleopochvy i prirodnye usloviya yuzhnorusskikh stepey v postkatakombnoe vremya [Paleosoils and Natural Conditions in South Russian Steppes in the Post-Catacomb Period]. Kratkie soobshcheniya Instituta arkheologii [Brief Reports of the Institute of Archaeology], 2011, iss. 225, pp. 144-154.

11. Demkin V.A., Borisov A.V., Demkina T.S., et al. Volgo-Donskie stepi $v$ drevnosti i srednevekovye (po materialam pochvenno-arkheologicheskikh issledovaniy) [Volga-Don Steppes in Ancient Times and in the Middle Ages (Based on the Materials of
Soil and Archaeological Research)]. Pushchino, SYNCHROBOOK Publ., 2010. 120 p.

12. Demkin V.A. Paleopochvovedenie $i$ arkheologiya [Paleo-Soil Science and Archaeology]. Pushchino, ONTI NTsBI AN SSSR, 1997. 213 p.

13. Kovda V.A., Bolshakov A.F. Vodno-solevoy rezhim pochv tsentralnoy chasti Kaspiyskoy ravniny [The Water-Salt Regime of Soils in the Central Part of the Caspian Plain]. Trudy konferentsii po pochvovedeniyu i fiziologii rasteniy. T. 1 [Proceedings of the Conference on Soil Science and Plants Physiology. Vol. 1]. Saratov, 1937, pp. 144-166.

14. Chernykh E.E., Mishina T.N., eds. Mezhdistsiplinarnaya integratsiya $v$ arkheologii [Interdisciplinary Integration in Archaeology]. Moscow, IA RAN Publ., 2016. 384 p.

15. Mimokhod R.A. Lolinskaya kultura. Severozapadnyy Prikaspiy na rubezhe srednego i pozdnego periodov bronzovogo veka [The Lolin culture. The North-Western Caspian Region at the Turn of the Middle and Late Bronze Age]. Materialy okhrannykh arkheologicheskikh issledovaniy. T. 16 [The Materials of Protective Archaeological Research. Vol. 16]. Moscow, IA RAN Publ., 2013. 568 p.

16. Mimokhod R.A.. Radiouglerodnaya khronologiya bloka postkatakombnykh kulturnykh obrazovaniy [Radiocarbon Chronology of the Block of Post-Catakomb Culture Formations]. Kratkie soobshcheniya Instituta arkheologii [Brief Reports of the Institute of Archaeology], 2011, iss. 225, pp. 28-53.

17. Mimokhod R.A. Srubnaya kultura Severozapadnogo Prikaspiya [The Timber-Grave Culture of the North-Western Caspian Region]. Trudy IV (XX) Vserossiyskogo arkheologicheskogo syezda $v$ Kazani. T. 1 [Proceedings of the $4^{\text {th }}$ (XX) All-Russian Archaeological Congress in Kazan. Vol. 1]. Kazan, 2014, pp. 609-614.

18. Rode A.A. Vodnyy rezhim i balans tselinnykh pochv polupustynnogo kompleksa [The Water Regime and Balance of Virgin Soils of a Semidesert Soil Complex]. Vodnyy rezhim pochv polupustyni [The Water Regime of Semi-Desert Soils]. Moscow, AN SSSR Publ., 1963, pp. 5-83.

19. Shilov V.P. Ocherki po istorii drevnikh plemen Nizhnego Povolzhya [Essays on the History of the Ancient Tribes of the Lower Volga Region]. Leningrad, Nauka Publ., 1975. 208 p.

20. Shishlina N.I. Potentsialnyy sezonnokhozyaystvennyy tsikl nositeley katakombnoy kultury Severo-zapadnogo Prikaspiya: problema rekonstruktsii [Potential Seasonal and Economic Cycle of Representatives of the Catacomb Culture of the NorthWestern Caspian Region: the Problem of Reconstruction]. Sezonnyy ekonomicheskiy tsikl naseleniya Severo-zapadnogo Prikaspiya $v$ bronzovom veke [Seasonal Economic Cycle of the 


\section{МЕЖДИСЦИПЛИНАРНЫЕ ИССЛЕДОВАНИЯ}

Population of the North-Western Caspian Region in the Bronze Age]. Moscow, Trudy GIM Publ., 2000, iss. 120 , pp. 54-71.

21. Shishlina N.I. Severo-zapadnyy Prikaspiy $v$ epokhu bronzy (V-III tys. do n.e.) [The North-Western Caspian Region in the Bronze Age (the $5^{\text {th }}-3^{\text {rd }}$ millennia BC)]. Moscow, Trudy GIM Publ., 2007, iss. 165.400 p.

22. Borisov A., Shishlina N. Climate changes and soil evolution in desert steppe zone of Russian Plain during the Bronze Age. Proceedings of the
International Multidisciplinary Scientific GeoConference Surveying Geology and Mining Ecology Management (SGEM 2017 Conference), 2017, vol. 17, iss. 32, pp. 77-84. DOI: 10.5593/sgem2017/ 32/S13.011.

23. Wendrich W., Barnard H. The Archaeology of Mobility: Definitions and research approaches. The Archaeology of Mobility. Old World and New World Nomadism. Los Angeles, Cotsen Institute of Archaeology Press, 2008, pp. 1-21.

\section{Information about the Authors}

Aleksandr V. Borisov, Candidate of Sciences (Biology), Head of the Laboratory of Archaeological Soil Science, Institute of Physical-Chemical and Biological Problems of Soil Science, Russian Academy of Sciences, Institutskaya St., 2, 142290 Pushchino, Russian Federation, a.v.borisovv@gmail.com, https:/ /orcid.org/0000-0001-5031-7477

Maksim V. Eltsov, Candidate of Sciences (Biology), Senior Researcher, Institute of PhysicalChemical and Biological Problems of Soil Science, Russian Academy of Sciences, Institutskaya St., 2, 142290 Pushchino, Russian Federation, m.v.eltsov@gmail.com, https://orcid.org/0000-0001-7886-8131

Sergey N. Udaltsov, Candidate of Sciences (Biology), Head of Center for Collective Use 'Physical and chemical methods of soil and ecosystem study', Institute of Physical-Chemical and Biological Problems of Soil Science, Russian Academy of Sciences, Institutskaya St., 2, 142290 Pushchino, Russian Federation, udaltsov@issp.serpukhov.su, https://orcid.org/0000-0003-1891-7944

Aleksandr V. Bukhonov, Candidate of Sciences (Biology), Senior Researcher, Institute of PhysicalChemical and Biological Problems of Soil Science, Russian Academy of Sciences, Institutskaya St., 2, 142290 Pushchino, Russian Federation, BuhonovAV@mail.ru, https://orcid.org/0000-0002-0219-9960

\section{Информация об авторах}

Александр Владимирович Борисов, кандидат биологических наук, заведующий лабораторией археологического почвоведения, Институт физико-химических и биологических проблем почвоведения РАН, ул. Институтская, 2, 142290 г. Пущино, Российская Федерация, a.v.borisovv@gmail.com, https://orcid.org/0000-0001-5031-7477

Максим Витальевич Ельцов, кандидат биологических наук, старший научный сотрудник, Институт физико-химических и биологических проблем почвоведения РАН, ул. Институтская, 2, 142290 г. Пущино, Российская Федерация, m.v.eltsov@gmail.com, https://orcid.org/0000-00017886-8131

Сергей Николаевич Удальцов, кандидат биологических наук, заведующий ЦКП «Физико-химические методы исследования почв и экосистем», Институт физико-химических и биологических проблем почвоведения РАН, ул. Институтская, 2, 142290 г. Пущино, Российская Федерация, udaltsov@issp.serpukhov.su, https://orcid.org/0000-0003-1891-7944

Александр Вячеславович Бухонов, кандидат биологических наук, старший научный сотрудник, Институт физико-химических и биологических проблем почвоведения РАН, ул. Институтская, 2, 142290 г. Пущино, Российская Федерация, BuhonovAV@mail.ru, https://orcid.org/00000002-0219-9960 